Campos Neutrais - Revista Latino-Americana de Relações Internacionais

Vol. 1 No 1, Janeiro - Abril de 2019

\title{
Eleições e Financiamentos de Campanhas no Brasil
}

Resenha de PEIXOTO, Vitor de Moraes. Eleições e Financiamentos de Campanhas no Brasil. Rio de Janeiro: Garamond, 2016. 196 p.

Maycon Yuri Nascimento Costa*

A obra de Vitor de Moraes Peixoto é fruto de uma bela tese de doutorado sob orientação do Professor e Pesquisador Jairo Nicolau. O autor apresenta uma grande contribuição para os estudos de financiamento de campanhas no Brasil, onde discute seus argumentos a partir de uma base de dados completa.

Para entender o trabalho é necessário saber que o autor apresenta diferentes problemas que também exigiram diferentes procedimentos ou desenhos metodológicos em cada capítulo, totalizandocinco capítulos na obra.

No prefácio escrito por Jairo Nicolau, identificam-se as principais perguntas em que se desenvolvem os argumentos de cada capítulo, que, respectivamente, a partir do segundo, sãoas seguintes:O que diferencia o sistema de financiamento do Brasil do de outras democracias?; Que fatores, além dos gastos de campanha, afetam o desempenho dos candidatos a deputado federal e deputado estadual?; Qual o efeito dos gastos de campanha sobre a competição política nas cidades brasileiras?; Qual o custo do horário eleitoral gratuito?

No primeiro capítulo o autor apresenta uma discussão sobre a teoria democrática e o sistema de financiamento, onde analisa como alguns países, a partir da $3^{\circ}$ onda da democratização, nas duas últimas décadas, ocorreram um crescimento da participação eleitoral, bem como um incremento da competição partidária, que culminaram com uma preocupação da "qualidade do regime democrático" e a preocupação dos limites institucionais de possibilitar um maior ou menor controle dos cidadãos, o que pode ser definido pela literatura como accountability (p.25).

O autor destaca que a principal discussão, no primeiro capítulo, que o debate sobre financiamentos de partidos"deve-se à estreita e indissociável relação existente entre as esferas de poder econômico e político, ou seja, entre dinheiro e eleições" (p.26).

\footnotetext{
* Bacharel em Ciências Sociais - Universidade Federal do Pará (2016) e Mestre em Ciência Política Universidade Federal do Pará (2018). E-mail: mayconyuri15@gmail.com
} 
Campos Neutrais - Revista Latino-Americana de Relações Internacionais Vol. 1 No 1, Janeiro - Abril de 2019

Essa relação entre dinheiro e eleições gera certo desafio aos arranjos institucionais, que possuem o propósito de limitar a influência nos gastos de campanhas, justamente por gerar um tipo de desvirtuamento do sistema representativo, já que o próprio ato de financiar um partido é uma forma de participação em um sistema democrático.

A principal pergunta que os teóricos que analisam os regimes democráticos, de acordo com a literatura levantada, éde que "em um sistema representativo desvirtuado, a quem realmente os partidos representam: os eleitores ou os financiadores de campanha?

Existem várias dimensões dessa questão, apresentadas pelo autor,entre elas está o de Przeworski (1994) que considera que nos regimes democráticos a competição abrange investimentos de três tipos de recursos: econômicos, organizacionais e ideológicos, que são empregados de forma desigual na disputa. Para Samples (2002) as eleições devem ser consideradas como um mercado que não deve possuir qualquer tipo de interferência regulatória.

Para aprofundar a discussão nesse debate, o autor apresenta o clássico conceito de Poliarquia de Robert Dahl (1997 [1972]) ondeafirma que para ser garantido esse tipo de sistema são necessários, no mínimo, três garantias, que são: liberdade de formar e aderir as organizações; liberdade de expressão; instituições para fazer com que as políticas governamentais dependam de eleições e outras manifestações de preferências (p.30).

Como um dos pressupostos teóricos o autor pretende testar o "efeito Jacobson", elaborado no contexto norte-americano, nas análises empíricas das eleições legislativasno Brasil, para deputados federais e estaduais/distritais. Para Gary Jacobson (1978) "os gastos dos candidatos à reeleição possuem impactos negativos sobre a proporção de votos, sendo, porém, positivos para os desafiantes" (p.35).

No capítulo dois o autor analisa os aspectos formais do sistema de financiamento dos partidos políticos, com levantamento de dados de 96 países, com foco no sistema regulatório brasileiro. A pergunta que norteia essa análise comparada é "Quem banca os custos da democracia?Sabe-se que a resposta dessa pergunta é que a manutenção das máquinas partidárias é por meio do setor público ou privado, porém, essa relação ocorre de diferentes maneiras nesse aspecto, através do sistema de regras eleitorais e partidárias de cada país. 
Campos Neutrais - Revista Latino-Americana de Relações Internacionais Vol. 1 No 1, Janeiro - Abril de 2019

Os 96 países democráticos que foram levantados pelo autor, podem ser destacados que em relação aos fundos públicos: 75\% apresentam alguma forma de distribuição de recursos públicos aos partidos. Existem críticas em relação a esse tipo de financiamento, porém, a crítica maior se encontra em relação ao financiamento privado, que estão sob atuação dos “big donnors" que poderiam causar distorções na competitividade eleitoral (p.48).

A obra de Vitor Peixoto é bem rica em aplicar modelos estatísticos para testar suas hipóteses e buscar possíveis associações dos sistemas políticos e o grau de regulação das agências eleitorais. Então, utiliza três modelos, cada um com uma variável dependente diferente. Assim, os resultados principais (p.63), são: Os sistemas de governo têm pouca ou nenhuma influência sobre o grau de intervenção estatal na competição eleitoral.Os sistemas eleitorais majoritários apresentaram-se como pouco restritivos em relação aos sistemas mistos (mas não em relação aos sistemas proporcionais) e a fragmentação partidária não afetou qualquer um dos índices de intervenção.

No capítulo três o autor parte de uma análise totalmente voltada para o cenário brasileiro, para discutir o impacto dos gastos de campanha nas eleições legislativas nacionais. A principal pergunta que se coloca é: "as características individuais dos candidatos afetam seus respectivos resultados eleitorais?”. Os resultados novamente se voltam para uma completa base de dados e, como procedimentos metodológicos a utilização da análise econométrica (OLS), que testou as variáveis em um contexto multidimensional. Essas foram as seguintes: Estado, Partido, Idade, Profissão, Escolaridade, Gênero e Gastos de Campanha.

Destacando os principais resultados, temos informações importantes do cenário brasileiro: 1 - A relação entre gastos de campanha e votos é inelástica, ou seja, gastar mais significa ter mais votos; 2 -Há diferença significativas entre os candidatos com filiação partidária distinta, ou seja, diferentemente do que pensam os políticos e parte dos analistas, os partidos também contam na arena eleitoral; 3 Mulheres possuem desempenhos piores que homens, ainda que o retorno dos gastos sejam maior que elas.

No capítulo quatro o autor aprofunda essa análise para o nível municipal, onde utiliza apenas os dados das eleições de 2008 como teste empírico. O objetivo que o autor coloca aqui é analisar sistematicamente a relação entre custos das campanhas e a competitividade eleitoral. O modelo utilizadoparte de diferentes variáveis, entre 
Campos Neutrais - Revista Latino-Americana de Relações Internacionais

Vol. 1 No $^{\circ}$, Janeiro - Abril de 2019

elas: índice de competitividade, número de partidos, número de eleitores, PIB municipal, taxa de analfabetismo, taxa de urbanização, existência de emissoras de rádio e TV e etc.

Novamente, destacando os principais resultados, podemos observar o seguinte cenário municipal: quanto mais desigual o município, maiores são os custos por eleitor das campanhas; os custos das campanhas aumentam nos municípios com maior PIB per capita; estruturas de comunicação encarecem as campanhas (emissoras de TVs e rádios; quanto maior for o grau de competição dos sistemas políticos, maiores os custos por eleitor.

No último capítulo do livro o autor faz uma investigação para descobrir o custo da democracia no Brasil e quais são os desafios regulatórios. A principal pergunta que norteia essa discussão é "quanto custa ao contribuinte a manutenção dos benefícios aos partidos políticos?”. Antes de tudo é preciso está atento que o Brasil é um dos países que mais apoio financeiro concede aos seus partidos, de forma direta e indireta (dinheiro do Fundo Partidário e através do Horário Gratuito de Propaganda Eleitoral e Propaganda Partidária Gratuita).

Os resultados apresentados em relação ao Fundo Partidário são de que em média foi gasto no ciclo eleitoral de 2011 e 2014, cerca de 1,5 bilhões, o que corresponde 385 milhões por ano. Já os gastos indiretos através de propaganda gratuitas no rádio e TV não foram possíveis de ser apresentados, mas o autor afirma que esses são os que mais oneram dos cofres públicos. Esses resultados nos fazem pensar sobre o quanto é gasto do dinheiro público para o financiamento de campanhas e se de fato podemos continuar mantendo esse tipo de financiamento.

Outra discussão que o autor ainda apresenta é de que as interferências dos grupos de interesses organizados no poder político, via campanhas, motiva debates acirrados sobre tipos de regulação e limites possíveis no sistema Brasileiro. A legislação brasileira permite que não só os partidos busquem financiamento, mas o candidato, individualmente, o que geram dois tipos de recursos: Comitês Partidários e Candidatos Individuais.

Por fim, o autor apresenta conclusões importantes para entender o sistema de financiamento de campanhas no Brasil. Uma delas é de que: 
Campos Neutrais - Revista Latino-Americana de Relações Internacionais Vol. 1 No 1, Janeiro - Abril de 2019

"O dinheiro é apenas parte dos recursos com potencialidade para alterar resultados eleitorais. Há recursos organizacionais (máquinas partidárias e de governo) que são mobilizadas pelos partidos e candidatos com o objetivo de angariar votos” (p.177).

Também acrescenta que "não será somente por aumento de regras mais proibitivas que se resolverão os problemas de intervenção de grupos organizados na política, muito menos casos de corrupção". Desse modo, se torna necessário que se criem mecanismos de fiscalização que possam agir de forma mais efetiva (p.179).

De forma geral, podemos concluir que essa obra de Vitor de Morais Peixoto é uma grande contribuição para se entender o debate entre a democracia representativa e o financiamento de campanha no Brasil. Além do mais, essa obra apresenta uma excelente contribuição metodológica de como aliar a questão empírica ao debate teórico. Sem dúvidas é uma das mais importantes obras para a Ciência Política Brasileira na atualidade, onde essas questões sobre reforma política encontram força. 